\title{
Seasonal and dose-dependent effects of intracerebroventricular leptin on LH secretion and appetite in sheep
}

\author{
D W Miller ${ }^{1}$, P A Findlay, M A Morrison ${ }^{1}$, N Raver ${ }^{2}$ \\ and C L Adam
}

Molecular Neuroendocrinology Group, Appetite and Energy Balance Division, Aberdeen Centre for Energy Regulation and Obesity, Rowett Research Institute,
Bucksburn, Aberdeen AB21 9SB, UK
${ }^{1}$ Department of Agriculture and Forestry, Aberdeen Centre for Energy Regulation and Obesity, University of Aberdeen, Aberdeen AB24 5UA, UK
${ }^{2}$ Institute of Biochemistry, Food Science and Nutrition, The Hebrew University of Jerusalem, Rehovot 76100, Israel
(Requests for offprints should be addressed to C L Adam; Email: cla@rri.sari.ac.uk)

Abstract

The role of leptin in neuroendocrine appetite and reproductive regulation remains to be fully resolved. A series of three experiments was conducted using adequately nourished oestradiol-implanted castrated male sheep. In a cross-over design $(n=6)$, responses to a single i.c.v. (third ventricle) injection of leptin $(0.5,1.0$ and $1.5 \mathrm{mg}$ ovine leptin (oLEP) and $1.0 \mathrm{mg}$ murine leptin (mLEP)), $\mathrm{N}$-methyl-D-aspartate (NMDA, $20 \mu \mathrm{g}$ ) or $0.9 \%$ saline (control) were measured in terms of $\mathrm{LH}$ secretion $(4 \mathrm{~h}$ post-injection compared with $4 \mathrm{~h}$ pre-injection) and appetite (during $2 \mathrm{~h}$ post-injection) in autumn (Experiment 1). NMDA and $1.0 \mathrm{mg}$ oLEP treatments were repeated in the same sheep in the following spring (Experiment 2). With an additional 12 sheep ( $n=18$ in cross-over design), responses to low-dose 'physiological' i.c.v. infusion of leptin (8 $\mathrm{ng} / \mathrm{h}$ for $12 \mathrm{~h}$ daily for 4 days), insulin $(0 \cdot 7 \mathrm{ng} / \mathrm{h})$ and artificial cerebrospinal fluid were measured in the next spring (Experiment 3). LH was studied over $8 \mathrm{~h}$ and appetite over $1 \mathrm{~h}$ on days 1 and 4 of infusion. In Experiment 1 (autumn), oLEP overall increased LH pulse frequency by up to $110 \%(P<0 \cdot 05)$, decreased $\mathrm{LH}$ pulse amplitude $(P<0 \cdot 05)$ and decreased appetite $(P<0 \cdot 05)$. mLEP reduced LH pulse amplitude $(P<0 \cdot 05)$ without significant effect on appetite, while NMDA reduced appetite $(P<0 \cdot 05)$ but had no effect on LH. In Experiment 2 (spring), LH responses were 'surge-like' with highly significant increases in the moving average LH concentration after $1.0 \mathrm{mg}$ oLEP $(P<0 \cdot 001)$ and after NMDA $(P<0 \cdot 001)$. Compared with similar analysis of Experiment 1 results, the LH response in spring was greater than that in autumn for both $1.0 \mathrm{mg}$ oLEP $(P<0.05)$ and NMDA $(P<0 \cdot 005)$. Conversely, unlike in autumn (Experiment 1$)$, there was no effect of $1.0 \mathrm{mg}$ oLEP or NMDA on appetite in the spring (Experiment 2). In Experiment 3 (spring), 'physiological' i.c.v. infusion of oLEP or insulin increased LH pulse frequency by up to $100 \%(P<0.001)$ compared with the control infusion on both days 1 and 4 , but there were no effects on appetite. These results indicate that intracerebral leptin both stimulates reproductive neuroendocrine output and decreases appetite in adequately nourished sheep. However, the responses of these two axes were dose-dependent and differentially affected by the time of year, suggesting dissociation of the neural pathways involved.

Journal of Endocrinology (2002) 175, 395-404

\section{Introduction}

The role of leptin in neuroendocrine regulation remains to be fully resolved. Although it has clearly been shown to act as a satiety factor within the hypothalamus, and acutely reduced circulating leptin levels with fasting evoke a powerful orexigenic drive, its role as a metabolic signal to the reproductive neuroendocrine axis is less clear (for review see Ahima et al. 2000). It appears that leptin plays a permissive action in this latter role, acting as a metabolic gate or threshold rather than a precise trigger to the gonadotrophin-releasing hormone $(\mathrm{GnRH})$ pulse generator. This hypothesis is supported by experiments in which leptin restores pulsatile luteinising hormone (LH) secretion in fasted rats and sheep (Nagatani et al. 1998, 2000), although direct leptin stimulation of LH in vivo has not been demonstrated in satiated animals. Pituitary LH secretion, which is strictly regulated by GnRH and which is readily measured in circulating blood, is commonly used as an in vivo measure of hypothalamic GnRH output (Clarke \& Cummins 1982).

Central leptin administration (i.c.v.) reduced food intake but did not affect LH secretion in adequately nourished ovariectomised ewes (Henry et al. 1999), but 
restored $\mathrm{LH}$ secretion in food-restricted ovariectomised ewes without affecting food intake (Henry et al. 2001). Morrison et al. (2001) also found that central leptin administration reduced food intake in adequately nourished and not in food-restricted ovariectomised ewes, but reported no effect on LH secretion in either group. Finally, Blache et al. (2000a) found that central leptin administration in adequately nourished intact rams decreased both food intake and LH secretion. The over-riding intake-depressing effect of leptin in adequately fed sheep in the above paradigms may have masked any potential GnRH-stimulating effect, i.e. GnRH stimulation was only observed when leptin was given to undernourished, and presumably leptin-deficient, animals. The compatibility of these data may be further confounded by the different times of year in which the studies were carried out, since a seasonal difference in sensitivity of the appetite axis to centrally administered leptin has since been reported for gonadectomised sheep (Clarke et al. 2001).

With the advent of assays able to detect leptin in cerebrospinal fluid (CSF), it is reported that the 'normal' or physiological concentration range of leptin in sheep CSF is about one-tenth to one-twentieth of the plasma concentration range (Blache et al. 2000b). In our experience, CSF from sheep across a range of adiposity and food intake has leptin concentrations ranging from 0.3 to $1.0 \mathrm{ng} / \mathrm{ml}$ (C L Adam \& M Marie, unpublished data using the assay of Marie et al. 2001). This equates to about one-tenth of the plasma concentration in 'lean' sheep with low intake ranging to 'fat' sheep with high food intake found previously by our group (Marie et al. 2001). The majority of studies that have employed central administration of leptin in order to elucidate its neuroendocrine role have used doses that may have produced intra-hypothalamic concentrations considerably in excess of the normal physiological range. For example, the central infusion doses employed in the foregoing studies in sheep varied from around $40 \mu \mathrm{g} / \mathrm{h}$ down to $40 \mathrm{ng} / \mathrm{h}$ (Henry et al. 1999, 2001, Blache et al. 2000a, Morrison et al. 2001). Effects of leptin on feed intake and GnRH secretion may be concentration dependent. Although no studies have directly addressed this issue, there is support for this hypothesis with the finding that the hypothalamic neuronal targets of leptin mediating recovery from starvation are apparently distinct from those that are activated by mild hyperleptinaemia (Ahima et al. 1999). Furthermore, a theoretical framework for the above postulate can be borrowed from the actions of insulin on feed intake and GnRH secretion. In rats, systemic doses of insulin that were high enough to cause hypoglycaemia stimulated feeding (Friedmann \& Granneman 1983) whereas sub-hypoglycaemic insulin doses suppressed feeding (Vanderweele et al. 1980). Moreover, effects of insulin on feed intake were dose-dependent when it was infused into the cerebral ventricles (Brief \& Davis 1984). In terms of effects at the level of the GnRH pulse-generator, Hileman et al. (1993) found that a single i.c.v. injection of insulin in sheep (500 ng-500 $\mu \mathrm{g}$ ) decreased LH secretion, whereas we have previously shown that a continuous infusion of insulin at a physiological dose of $570 \mathrm{pg} / \mathrm{h}$ increased LH pulse frequency (Miller et al. 1995).

In the present study, a series of three experiments was conducted using the oestradiol-implanted male castrated sheep model (Adam \& Findlay 1998, Nagatani et al. 2000). This model produces constant physiological concentrations of gonadal steroid feedback, obviating the effects of seasonal fluctuations in circulating concentrations. This provides tonic restraint to $\mathrm{GnRH} / \mathrm{LH}$ pulsatility without which stimulation of this axis would be harder to detect. Centrally administered (third cerebral ventricle, i.c.v.) N-methyl-D-aspartate (NMDA) was used as a positive control for $\mathrm{GnRH} / \mathrm{LH}$ stimulation since it is a recognised secretagogue for GnRH and the magnitude of the response is photoperiod dependent in sheep (Viguie et al. 1995). The objectives were to determine whether a single i.c.v. injection of leptin would stimulate $\mathrm{GnRH} / \mathrm{LH}$ before the response is confounded by the GnRHsuppressive effect of a leptin-induced reduction in food intake (Experiment 1), whether the responses of both the appetite and GnRH/LH axes were affected by the time of year within the ovine breeding season (Experiment 2), and whether the responses of both of these axes to a low 'physiological' i.c.v. infusion dose of leptin differed from previous 'pharmacological' paradigms (Experiment 3).

\section{Materials and Methods}

All experimental procedures involving animals were conducted under the authority of the Animals (Scientific Procedures) Act of 1986 and received prior approval from the local Ethical Review Committee.

\section{Animals and i.c.v. cannulation}

All sheep were Suffolk $\times$ Greyface adult male castrates (approximately 1 year old at surgery) with average live weight $52 \pm 1.0 \mathrm{~kg}$ and body condition score $2 \cdot 4 \pm 0.05$ (after Russel et al. 1969). They were housed in individual pens in natural lighting in Aberdeen $\left(52^{\circ} \mathrm{N}\right)$ and given a complete chaff-based diet twice daily at $0800 \mathrm{~h}$ and $1700 \mathrm{~h}$ in amounts designed to maintain live weight (maintenance fed). Water was provided ad libitum. They were acclimatised to these conditions and to frequent human contact prior to surgery. Cannulation of the third cerebral ventricle, as reported by Miller et al. (1995), was undertaken in 24-h fasted sheep maintained on halothane anaesthesia (2\% halothane; Concord Pharmaceuticals Ltd, Dunmow, Essex, UK). While under general anaesthesia, each sheep was given two subcutaneous oestradiolcontaining implants made from Silastic tubing (Adam \& Findlay 1998) which raised plasma oestradiol concentrations to a steady $3.93 \pm 0.45 \mathrm{pg} / \mathrm{ml}$ (measured during 
each experiment by radioimmunoassay; Mann et al. 1995). Immediately before surgery, sheep received antibiotics (ampicillin $500 \mathrm{mg} / \mathrm{ml}$; Penbritin; SmithKline Beecham, and gentamicin $50 \mathrm{mg} / \mathrm{ml}$; Pangram 5\%; Bimeda UK, Llangefni, Anglesey, UK) and analgesics (carprosen $50 \mathrm{mg} / \mathrm{ml}$; Rimadyl; Pfizer and buprenorphine $0.3 \mathrm{mg} /$ ml; Temgesic; Schering-Plough Ltd, Welwyn Garden City, Herts, UK). Antibiotic (gentamicin) was given daily for 3 days and analgesia (buprenorphine) was given as required. The sheep were allowed a minimum post-operative recovery period of 4 weeks prior to experimentation.

\section{Experiment 1}

In October-November 1999 (late autumn), six surgically prepared sheep were given a single $0.1 \mathrm{ml}$ injection into the third cerebral ventricle (i.c.v.) of each of the following in a balanced cross-over (Latin square) design, with 1-week intervals between treatments: $0.9 \%$ saline negative control, or (dissolved in $0.9 \%$ saline) $0.5 \mathrm{mg}$ recombinant ovine leptin ( 0.5 oLEP, supplied by Arieh Gertler; Gertler et al. 1998), $1.0 \mathrm{mg}$ ovine leptin (1.0 oLEP), $1.5 \mathrm{mg}$ ovine leptin $(1.5 \mathrm{oLEP}), 20 \mu \mathrm{g}$ NMDA positive control (NMDA; Sigma International, Poole, Dorset, UK) or $1.0 \mathrm{mg}$ recombinant murine leptin $(1.0 \mathrm{mLEP}$; courtesy of $\mathrm{NIH}$. The NMDA dose rate was calculated from published effective doses for i.v. administration in sheep (Viguie et al. 1995) and for i.c.v. administration in rhesus monkeys (Gay et al. 1993). Starting at $0800 \mathrm{~h}$, blood was taken via a temporary jugular catheter every 15 min for $4 \mathrm{~h}$ before and $4 \mathrm{~h}$ after i.c.v. injection and plasma was stored at $-20{ }^{\circ} \mathrm{C}$ prior to $\mathrm{LH}$ analysis. Voluntary food intake (VFI) was determined by measuring the ad libitum consumption of the chaff-based diet during the 2-h period immediately post-injection.

\section{Experiment 2}

In April 2000 (spring), the NMDA and 1.0 oLEP treatments of Experiment 1 were repeated in each of the same six sheep, with a 1-week interval between cross-over of treatments. Blood was taken via a jugular catheter every $15 \mathrm{~min}$ for $4 \mathrm{~h}$ before and $4 \mathrm{~h}$ after i.c.v. injection, and plasma LH and VFI were measured as before. Control VFI measurements were obtained in all sheep on two occasions in the week prior to the start of the experiment; during the 2-h test period the sheep were handled every $15 \mathrm{~min}$ to simulate blood sampling.

\section{Experiment 3}

In March-April 2001 (spring), the same six sheep of Experiments 1 and 2, together with 12 additional surgically prepared steroid-replaced male castrates, were allocated into two equal groups. During the 6 weeks of
Experiment 3, nine sheep per week were undergoing treatment whilst the other nine had a 1-week rest interval. Each sheep was given each of three infusion treatments in a randomised cross-over design. Infusions into the third ventricle were performed for $12 \mathrm{~h} /$ day $(0800-2000 \mathrm{~h})$ for 4 consecutive days at a flow rate of $5 \mu \mathrm{l} / \mathrm{min}$ via a battery-powered syringe driver (Graseby Medical Ltd, Watford, Herts, UK) attached to a harness on the animal's back. The infusates were prepared in a carrier of artificial CSF (aCSF) as described by Nilsson et al. (1991) and which is similar in composition to sheep CSF (Pollay et al. 1972). The infusion treatments were: aCSF control, porcine insulin in aCSF $(0.7 \mathrm{ng} / \mathrm{h}$; biopotency $=24.0 \mathrm{IU} / \mathrm{mg}$; Sigma International) or ovine leptin in aCSF $(8 \cdot 0 \mathrm{ng} / \mathrm{h})$. The insulin infusion treatment acted as a positive control as it had been previously shown by Miller et al. (1995) to stimulate LH secretion in male sheep when infused into the third cerebral ventricle using the same infusion protocol.

Jugular catheters were inserted the day before the start of i.c.v. infusion and remained in place for blood sampling during the 4-day infusion. On days 1 and 4 of infusion, starting at $0800 \mathrm{~h}$, blood samples were taken every $15 \mathrm{~min}$ for $8 \mathrm{~h}$ for LH analysis, and VFI was determined by measuring the ad libitum consumption of the chaff-based diet during a $1-\mathrm{h}$ period from $1400 \mathrm{~h}$ to $1500 \mathrm{~h}$.

\section{Calculation of insulin and leptin infusion doses in Experiment 3}

The dose and infusion rate for insulin, derived from CSF insulin parameters described by Davson et al. (1987), had previously produced physiological increases in ovine CSF insulin concentrations (Miller et al. 1995). The dose and infusion rate for leptin were calculated using the same parameters with the inclusion of the basal leptin concentration in sheep CSF. The dose for leptin was designed to produce a constant concentration in the third ventricle of approximately four times the physiological level for a 'maintenance-fed' sheep (about $0.3 \mathrm{ng} / \mathrm{ml}$ ) to values approximating a 'well-fed' sheep (about $1 \cdot 2 \mathrm{ng} / \mathrm{ml}$ ) for the duration of the $12-\mathrm{h}$ infusion per day.

\section{LH radioimmunoassay}

LH concentrations were determined in duplicate aliquots of plasma samples with the assay technique of Adam et al. (1998) using radioimmunoassay reagents provided by NIDDK (Rockville, MD, USA) and expressed in terms of the reference standard NIDDK-oLH-1-2. Intra- and interassay coefficients of variation averaged 5 and $10 \%$ respectively, and the detection limit was $0.05 \mathrm{ng} / \mathrm{ml}$. The effect of the interassay variation on comparisons of LH pulse variables between treatments, and between Experiments 1 and 2, was avoided by assaying all samples from one animal in the same assay run. 
(a)

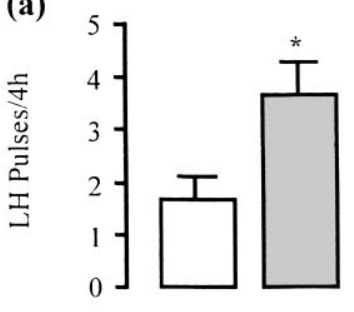

(c)

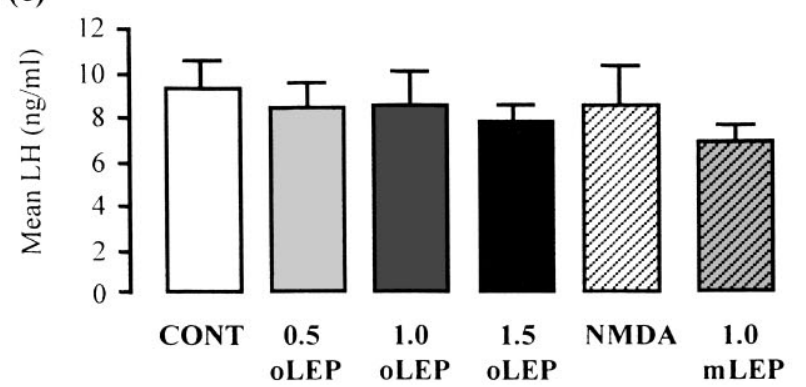

(b)

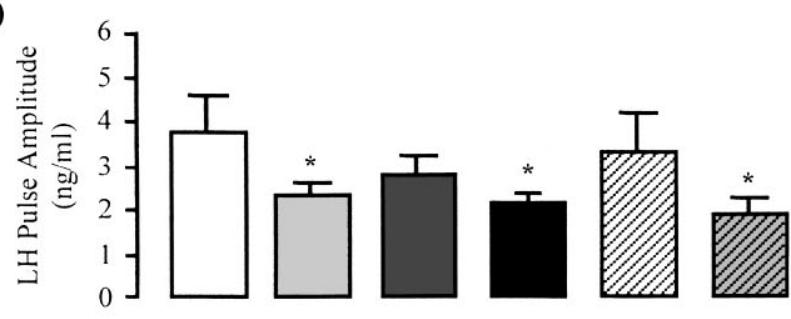

(d)

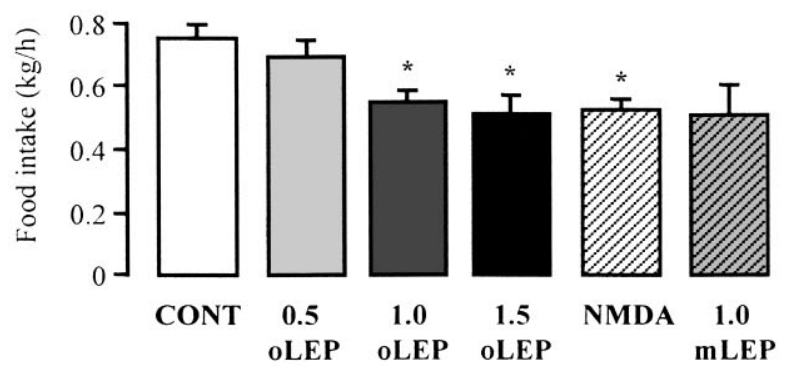

Figure 1 (a) LH pulse frequency, (b) LH pulse amplitude, (c) mean LH concentration and (d) VFI of steroid-replaced castrated male sheep $(n=6)$ after a single i.c.v. (third ventricle) injection of $0.9 \%$ saline (CONT; open bars), 0.5 oLEP (light grey bars), 1.0 oLEP (dark grey bars), 1.5 oLEP (solid bars), $20 \mu \mathrm{g}$ NMDA (hatched white bars) or $1.0 \mathrm{mLEP}$ (hatched grey bars) (Experiment 1 ; autumn). Values are means \pm S.E.M. ${ }^{*} P<0 \cdot 05$ compared with CONT.

\section{LH pulse analysis}

The LH values from the serial samples were analysed with a modified version of the 'Pulsar' algorithm developed by Merriam \& Wachter (1982) and modified for the Apple Macintosh computer ('Munro'; Zaristow Software, Haddington, East Lothian, UK). The G parameters (the number of standard deviations by which a peak must exceed the baseline in order to be accepted; $G_{1}-G_{5}$ ) were set at $3,2 \cdot 5,1 \cdot 9,1 \cdot 2$ and $0 \cdot 9$, these being the requirements for pulses composed of one to five samples that exceed the baseline respectively. The Baxter parameters describing the parabolic relationship between the concentration of hormone in a sample and the standard deviation (assay variation) about that concentration were $0.25132\left(b_{1}\right.$, the y intercept), $0 \cdot 06557\left(b_{2}\right.$, the $\mathrm{x}$ coefficient) and $0 \cdot 00291$ $\left(b_{3}\right.$, the $x^{2}$ coefficient). Pulse frequency, mean pulse amplitude and mean concentration of LH were calculated for each profile.

\section{Statistical analysis}

LH pulse frequency data were tested for homogeneity of variance and were found to be normally distributed. ANOVA was therefore used to compare treatment effects on feed intake, LH pulse frequency, LH pulse amplitude and mean LH concentration, accounting for individual animal variation and the cross-over design. When the main effect of the infusion treatments was significant
$(P<0 \cdot 05)$, post-hoc one-way ANOVA was used to test for differences between specific treatments. In Experiment 2, identification of individual $\mathrm{LH}$ pulses after treatment was difficult due to the surge-like nature of the response (Fig. $2 \mathrm{~b}$ ), with $\mathrm{LH}$ pulses tending to merge with each other. Pulse interactions were therefore removed by calculating the moving average of five consecutive samples (Fig. 2d) and repeated measures ANOVA was conducted on these moving average values.

\section{Results}

\section{Experiment 1}

There was no difference between treatment groups prior to injection, and no difference between the pre- and post-injection values in the control group, for any of the LH pulse variables measured. Overall, the ovine leptin treatments increased LH pulse frequency $(P<0.05)$ and decreased pulse amplitude $(P<0 \cdot 05$; Fig. 1$)$. Specifically, the 0.5 oLEP and 1.0 oLEP treatments significantly $(P<0 \cdot 05)$ increased LH pulse frequency by $110 \%$ and $70 \%$ respectively, compared with the negative control injection (CONT), whereas the $72 \%$ increase after 1.5 oLEP failed to reach significance (Fig. 1a). The 0.5 oLEP and 1.5 oLEP treatments significantly $(P<0.05)$ reduced pulse amplitude by $42 \%$ and $45 \%$ respectively, compared with the CONT treatment, whereas the response to $1 \cdot 0$ oLEP 
was not significant (Fig. 1b). None of the ovine leptin treatments altered the mean LH concentrations (Fig. 1c). The murine leptin $(1.0 \mathrm{mLEP})$ reduced pulse amplitude by $47 \%(P<0 \cdot 05)$ but had no effect on the other LH pulse variables. The positive control (NMDA) treatment had no significant effect on any of the LH pulse variables.

Overall, the ovine leptin treatments reduced VFI $(P<0 \cdot 05$; Fig. $1 \mathrm{~d})$. Specifically, $1.5 \mathrm{oLEP}$ and $1 \cdot 0$ oLEP $(P<0 \cdot 05)$ reduced VFI by $35 \%$ and $28 \%$ respectively, compared with the CONT treatment, whereas 0.5 oLEP had no significant effect. The NMDA treatment reduced VFI by $31 \%(P<0 \cdot 05)$, compared with the CONT treatment, but the $32 \%$ reduction after $1.0 \mathrm{mLEP}$ treatment failed to reach significance.

\section{Experiment 2}

There was no difference in any of the LH pulse variables between groups in the $4 \mathrm{~h}$ before treatment (Fig. 2a). Neither $1 \cdot 0$ oLEP nor NMDA significantly altered any of the LH variables compared with pre-injection values, although there was an apparent trend for both 1.0 oLEP and NMDA to increase LH pulse amplitude $(P=0.09)$ and mean concentration $(P=0 \cdot 06)$. However, examination of individual pulse profiles revealed that LH pulses were tending to merge together into a 'surge-like' response post-injection, making identification of individual pulses both difficult and inappropriate (Fig. 2b). A better representation of the effects of $1.0 \mathrm{oLEP}$ and NMDA was found by calculating a moving average of five consecutive samples of LH concentration in order to smooth the pulse effect (Fig. 2d). Repeated measures ANOVA indicated that there was a highly significant increase in the moving average LH concentration after 1.0 oLEP $(P<0 \cdot 001)$ and NMDA $(P<0 \cdot 001)$ i.c.v. injections. Repeated measures analysis also revealed a significant effect of time of year on the moving average $\mathrm{LH}$ concentration when comparing the 1.0 oLEP $(P<0.05)$ and NMDA $(P<0 \cdot 005)$ treatments between Experiments 1 and 2 (Fig. 2d).

Although there was no saline-injected (control) treatment in this experiment, the effect on VFI of the 1. 0 oLEP and NMDA treatments was compared with control VFI measurements obtained during the week before i.c.v. injections commenced (Fig. 2c). There was no effect detected of either of the i.c.v. treatments on VFI. However comparison with VFI values obtained in Experiment 1 revealed a significant effect of time of year on VFI responses to the 1.0 oLEP $(P<0 \cdot 05)$ and NMDA $(P<0 \cdot 005)$ treatments (Fig. 2c).

\section{Experiment 3}

Overall, the leptin and insulin treatments increased $\mathrm{LH}$ pulse frequency $(P<0 \cdot 0001)$ with no effect on any of the other LH pulse variables (Figs 3 and 4). Specifically, on day 1 the leptin $(P<0 \cdot 01)$ and insulin $(P<0 \cdot 05)$ infusion treatments increased LH pulse frequency by $90 \%$ and $55 \%$ respectively, compared with the control infusion. On day 4 , the leptin $(P<0 \cdot 005)$ and insulin $(P<0 \cdot 01)$ infusion treatments increased LH pulse frequency by $100 \%$ and 95\% respectively. There was no effect of either the leptin or insulin infusion treatments on VFI (Fig. 3d).

\section{Discussion}

Our data strongly support the hypothesis that intracerebral leptin is a metabolic modulator of not only appetite, but also of GnRH secretion. The results have demonstrated for the first time the stimulation of LH pulsatility by physiological amounts of leptin infused into the third cerebral ventricle of adequately nourished sheep, with no simultaneous effect on appetite. Although the stimulatory effect of leptin was manifest as an increase in LH pulse frequency, this is indicative of activation of the hypothalamic GnRH neurones (Clarke \& Cummins 1982). In addition, the results demonstrate that responses to a single pharmacological i.c.v. leptin injection are seasonally dependent yet distinct for the appetite and reproductive neuroendocrine axes.

Previous in vivo demonstrations of $\mathrm{LH}$ stimulation by leptin have been confined to the restoration of $\mathrm{LH}$ secretion in sheep that were fasted or undernourished, and therefore presumably leptin deficient (Nagatani et al. 2000, Henry et al. 2001). The failure to demonstrate LH stimulation by i.c.v. leptin in previous studies of adequately fed sheep (Henry et al. 1999, 2001, Blache et al. 2000b, Morrison et al. 2001) could be explained by the design of these experiments such that the over-riding intake-depressing effect of leptin over the 3- to 8-day infusion protocols counteractively inhibited GnRH secretion. In support of our original hypotheses, by looking at immediate responses to a single i.c.v. injection of leptin we were able to demonstrate LH stimulation despite a transient reduction in appetite (Experiment 1) and, moreover, by employing a much lower 'physiological' i.c.v. infusion dose of leptin we were able to detect LH stimulation with no concurrent effect on appetite (Experiment 3). The intriguing findings of the present studies with respect to LH stimulation by i.c.v. leptin was the difference in the magnitude of the response at the different times of the year and the difference in the nature of the response to 'physiological' as opposed to 'pharmacological' administration. Thus, in the late autumn (Experiment 1; short days), LH pulse frequency was stimulated and LH pulse amplitude decreased by a single 'pharmacological' i.c.v. leptin injection, whereas the same treatment in spring (Experiment 2; long days) induced a large surge-like release of LH that masked any increase in pulsatility (Fig. $2 \mathrm{~b}$ and $\mathrm{d}$ ); however, a 'physiological' i.c.v. infusion of leptin in the spring did not induce a surge-like response but specifically increased LH pulse frequency (Fig. 4). 
(a)
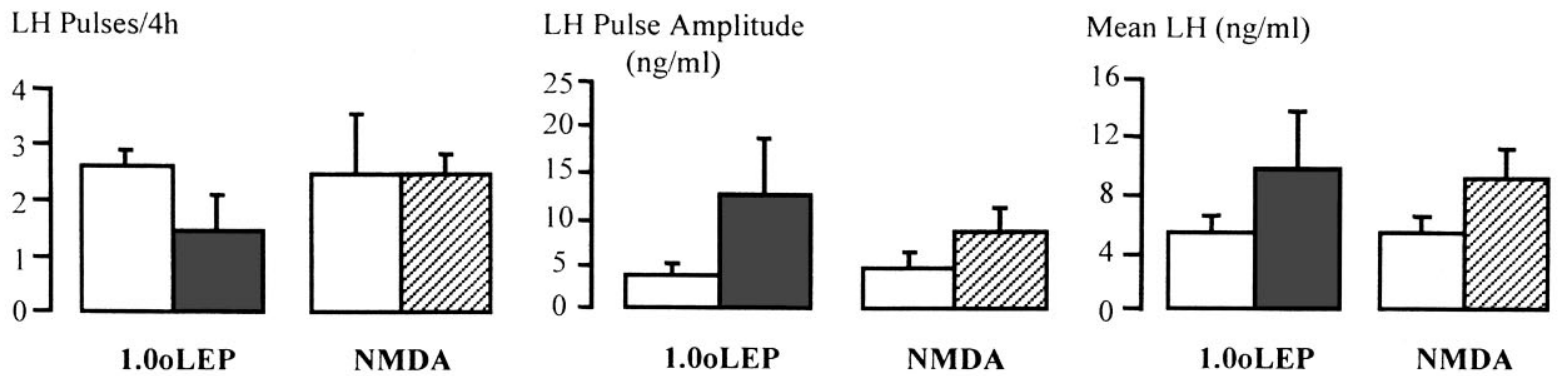

(b)

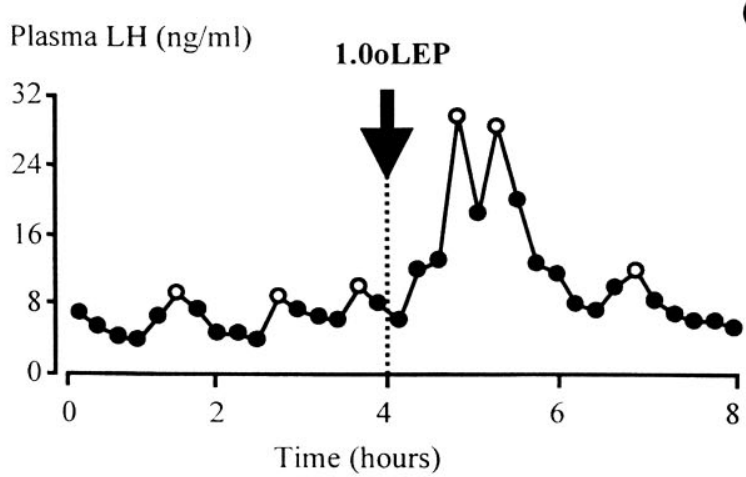

(d)

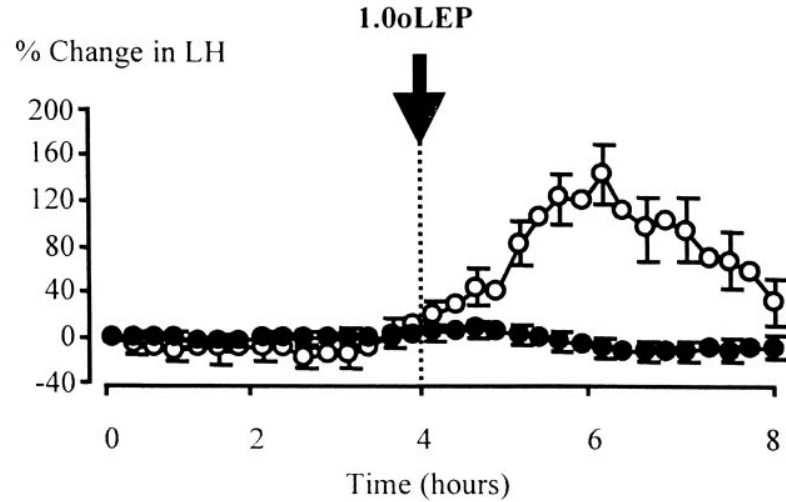

(c)

Food intake $(\mathrm{kg} / \mathrm{h})$
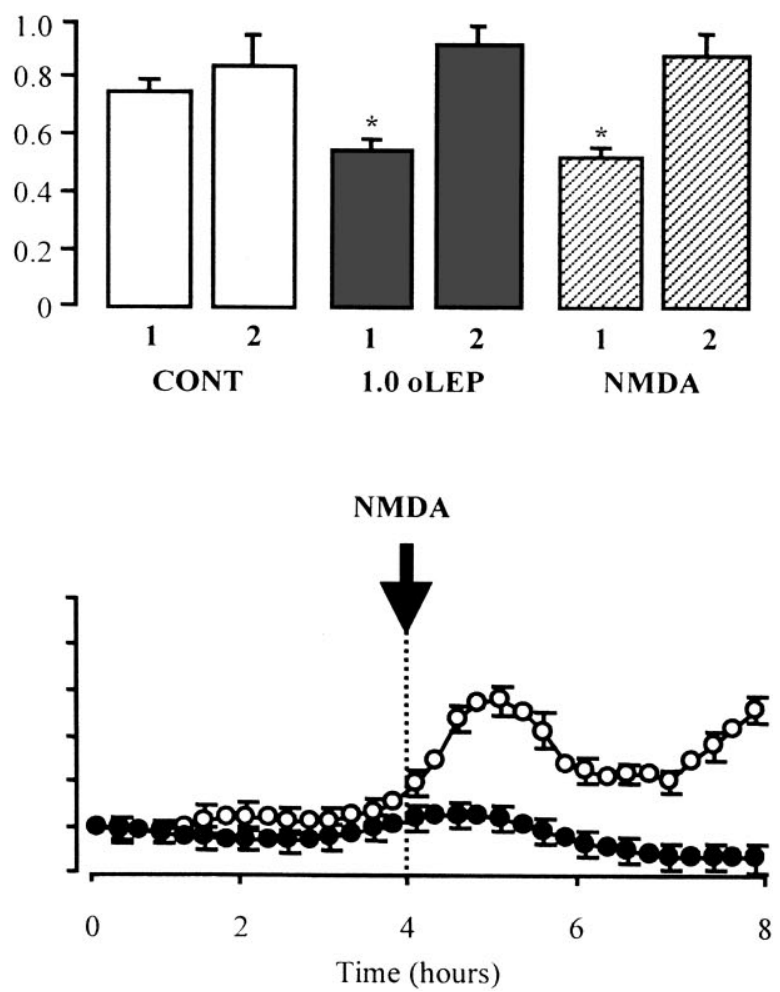

Figure 2 (a) LH pulse frequency, LH pulse amplitude and mean LH concentration of steroid-replaced castrated male sheep ( $n=6)$ after a single i.c.v. (third ventricle) injection of $1.0 \mathrm{oLEP}$ (grey bars) or $20 \mu \mathrm{g}$ NMDA (hatched bars) (Experiment 2; spring). Control samples (open bars) were taken for $4 \mathrm{~h}$ prior to injection. (b) Representative individual $\mathrm{LH}$ profile showing surge-like response after i.c.v injection of $1 \cdot 0$ oLEP (open symbols indicate significant pulses) (Experiment 2). (c) VFI during $2 \mathrm{~h}$ after CONT, $1 \cdot 0$ oLEP and NMDA treatments in Experiments 1 and 2. (d) Smoothed plasma LH profiles (5-day moving average) showing responses to 1.0 oLEP and NMDA in Experiment 1 (autumn, November; solid symbols) and Experiment 2 (spring, April; open circles). Values are means \pm S.E.M. For clarity, S.E.M. values are shown only for every second point in (d). The arrows indicate the time of i.c.v. injection in (b) and (d).

The NMDA treatment was ineffective as a positive control in the autumn (Experiment 1). However, the dose rate was extrapolated from a peripheral dose used in sheep (Viguie et al. 1995) and an i.c.v. dose for rhesus monkeys (Gay et al. 1993) and may have been sub-optimal at this time of year. Nonetheless, the same dose in the spring was effective (Experiment 2; Fig. 2d), in agreement with the seasonal sensitivity reported for the LH response to
NMDA in sheep (Viguie et al. 1995). The reason for a seasonal difference in the $\mathrm{GnRH}$ response to leptin is open to speculation. It is unlikely to be attributable to seasonal changes in gonadal steroid concentrations interacting with the actions of leptin (Ainslie et al. 2001, Kimura et al. 2002) since steroid-clamped oestradiol-implanted castrates were used. However, the similar, seasonally dependent responses of $\mathrm{LH}$ secretion and appetite to NMDA in the 
(a)

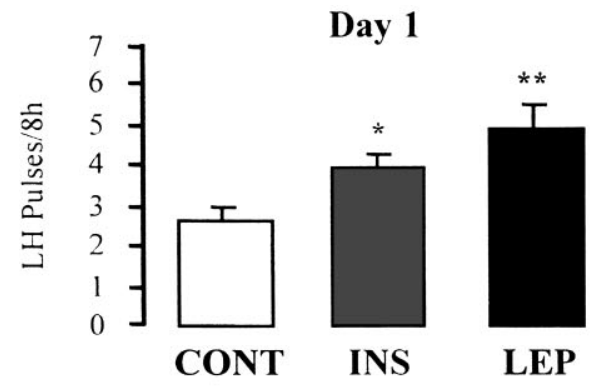

Day 4

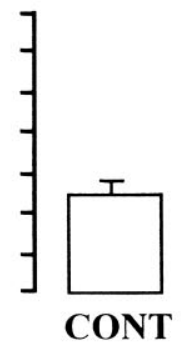

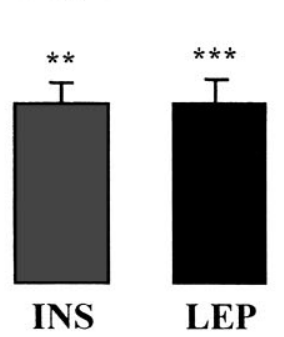

(b)

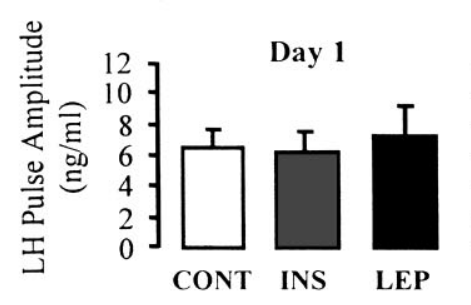

(d)

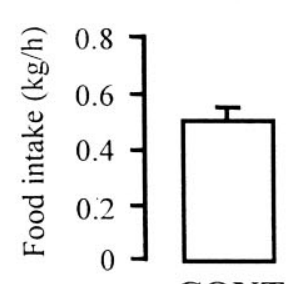

CONT

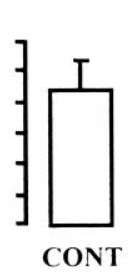

Day 4

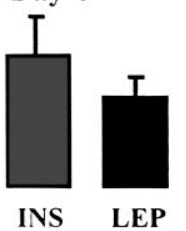

Day 1

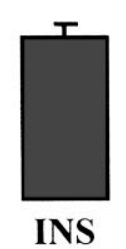

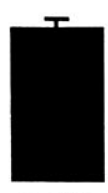

LEP

(c)
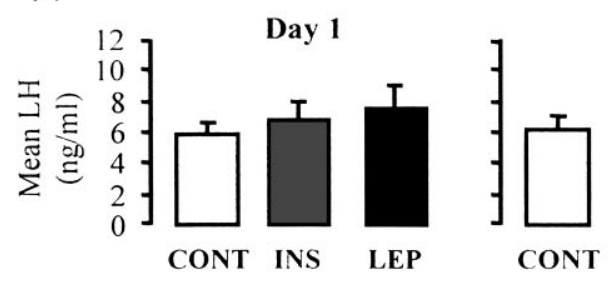

Day 4

Day 4

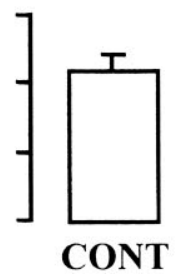

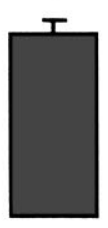

INS

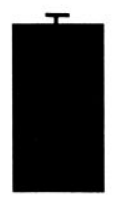

LEP

Figure 3 (a) LH pulse frequency, (b) LH pulse amplitude, (c) mean LH concentration and (d) VFI of steroid-replaced castrated male sheep $(n=18)$ on days 1 and 4 of the following infusion treatments ( 4 days, $12 \mathrm{~h} /$ day) into the third cerebral ventricle: aCSF (CONT; open bars), insulin (INS, $0.7 \mathrm{ng} / \mathrm{h}$; grey bars) or ovine leptin (LEP, $8 \mathrm{ng} / \mathrm{h}$; solid bars) (Experiment 3; spring). Values are means \pm S.E.M. ${ }^{*} P<0 \cdot 05$,

${ }^{* *} P<0 \cdot 01,{ }^{* *} P<0 \cdot 005$ compared with CONT.

present study (in agreement with Viguie et al. 1995) are consistent with leptin acting in part via glutamatergic pathways. Glutamatergic pathways operate in the hypothalamus to regulate the release of peptides and catecholamines to control the secretion of $\mathrm{GnRH} / \mathrm{LH}$ (Kumar et al. 1993). NMDA receptors are found in regions of the ovine hypothalamus that are known to have important functions in seasonality and control of reproduction and appetite (Anderson et al. 1999), and manipulation of glutamatergic neurotransmission affects the rate of photoperiodically regulated sexual maturation in hamsters (Ebling \& Cronin 1998). Finally, leptin-NMDA interactions have been reported, at least in the hippocampus, in which leptin facilitated NMDA receptor function by rapidly enhancing NMDA-induced increases in intracellular calcium levels (Shanley et al. 2001).

A plausible explanation for the seasonal change in response to leptin is that photoperiod (short daylength) is the main cue for stimulation of $\mathrm{GnRH}$ pulsatility in the sheep (e.g. for review see Karsch et al. 1984), effectively over-riding additional nutritional stimulation in the autumn. When photoperiod support is waning as the days lengthen in the spring, there is evidence that the reproductive axis becomes more receptive to nutritional stimulation since improved nutrition at this time delays both anoestrus in ewes (Knight et al. 1983) and testicular regression in rams (Martin et al. 1994).

Although there was a trend towards negative dosedependence of the LH pulsatile response within the pharmacological doses of i.c.v. leptin used in Experiment 1 , the more striking difference in response was seen between the 'pharmacological' and 'physiological' doses of Experiments 2 and 3 respectively, given at the same time of year. In other words, a modest increase in intracerebral leptin was more stimulatory to the frequency of $\mathrm{GnRH}$ pulses than was a large increase in leptin, which induced a greater, surge-like release of $\mathrm{GnRH}$. This is not without precedent since a dose-dependent response exists for the effects of i.c.v. insulin on LH secretion. Hileman et al. (1993) found that a large i.c.v. dose of insulin (500 ng or more in a single injection) decreased $\mathrm{LH}$ secretion, whereas 'physiological' i.c.v. insulin infusion at 0.7 and $0.6 \mathrm{ng} / \mathrm{h}$ stimulated $\mathrm{LH}$ secretion in the present trial and in the study of Miller et al. (1995) respectively. The 

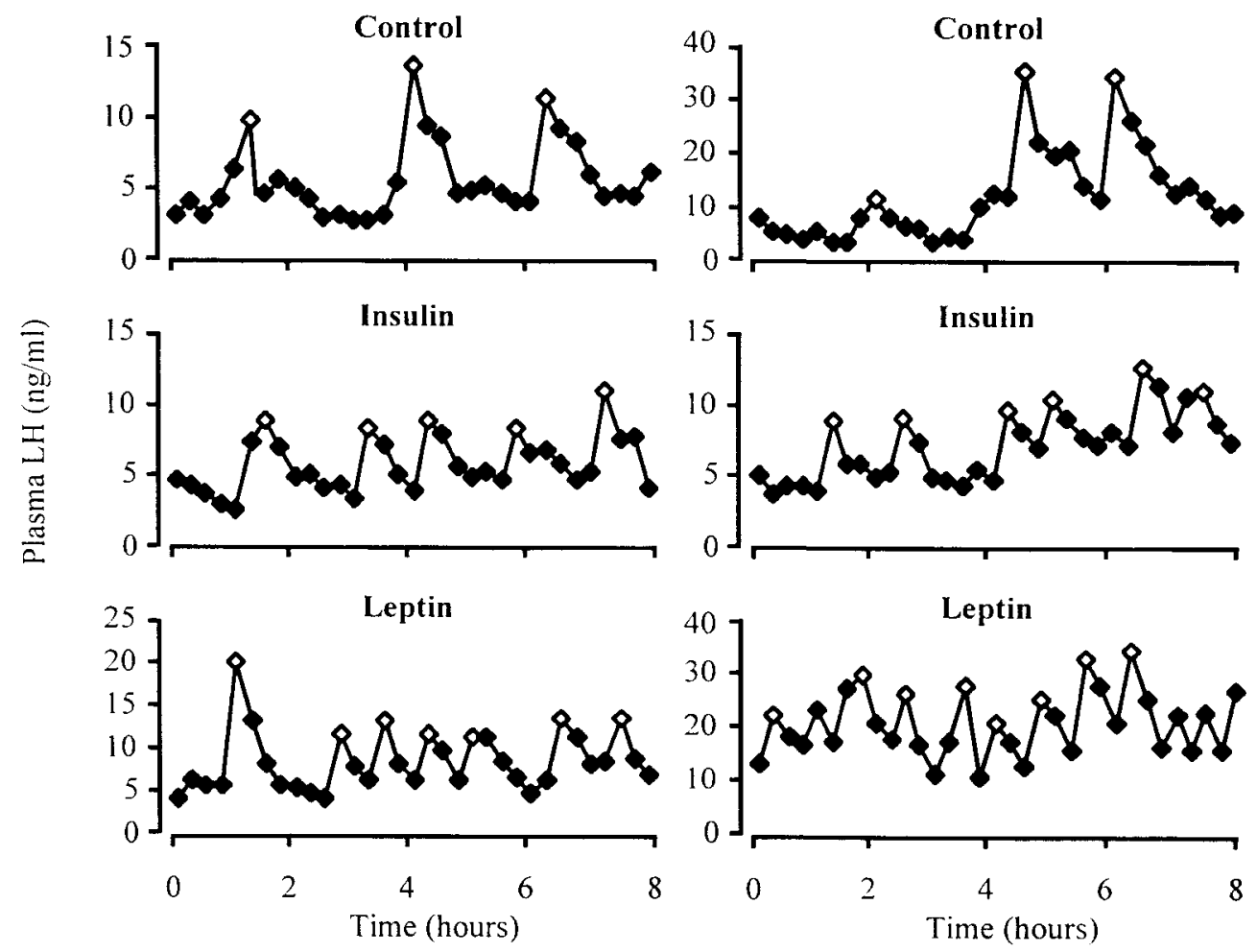

Figure 4 Representative individual LH profiles showing responses in two steroid-replaced castrated male sheep on day 4 of the following infusion treatments $(12 \mathrm{~h}$ /day) into the third cerebral ventricle: aCSF (control; top two panels), insulin $(0.7 \mathrm{ng} / \mathrm{h}$; middle two panels) or ovine leptin ( $8 \mathrm{ng} / \mathrm{h}$; bottom two panels). The open symbols indicate significant pulses.

similarity of the appetite and LH responses between i.c.v. infusions of insulin and leptin in the present study could be indicative of similar pathways of action. Indeed, insulin may interact with the leptin receptor $(\mathrm{OB}-\mathrm{Rb})$, since i.c.v. insulin down-regulates $\mathrm{OB}-\mathrm{Rb}$ gene expression in the sheep hypothalamus (Daniel et al. 2000) and gene expression for both insulin receptor and $\mathrm{OB}-\mathrm{Rb}$ is found in the same (arcuate) hypothalamic nucleus in sheep (Z A Archer, P A Findlay \& C L Adam, unpublished observations; Williams et al. 1999).

The seasonal difference in sensitivity of the appetite axis to i.c.v. leptin in the present study using oestradiolimplanted castrated sheep, with intake inhibited by leptin in the autumn but not in the spring, is opposite to the responses reported for gonadectomised sheep (Clarke $e t$ al. 2001). However, in both studies, the appetite-depressing effect of leptin was greatest when the measured basal voluntary intake was at its lowest. The disparity may be resolved when such studies are conducted in controlled artificial photoperiods rather than in natural photoperiods. Nonetheless, unlike in the present study, the sheep used by Clarke et al. (2001) did not have gonadal steroid replacement and it is suggested that oestradiol is required to facilitate leptin actions in the brain (Bennett et al. 1998, Pelleymounter et al. 1999, Ainslie et al. 2001, Kimura et al.
2002). Photoperiodic modulation of leptin-induced body weight (or fat) loss is seen in the Siberian hamster, with sensitivity to leptin in two separate studies found to be greatest in a short- as opposed to a long-day photoperiod (Atcha et al. 2000, Klingenspor et al. 2000). In seasonal species like Siberian hamsters and sheep, endogenous leptin concentrations increase in long days when appetite, body weight and adiposity increase, and decrease in short days when appetite, body weight and adiposity decrease (Atcha et al. 2000, Klingenspor et al. 2000, Marie et al. 2001). It is postulated therefore that a transient period of relative leptin insensitivity in long days is necessary to prevent the elevated leptin levels counteracting the environmental adaptation of photoperiod-driven increases in intake and body weight in these species.

The apparent seasonal change in sensitivity of the appetite axis to leptin in the present study may have been attributable to differences in effective energy balance between the sheep at the different times of year. Appetite drive is higher in the spring (longer days) than in the autumn (shorter days), as suggested by the non-significant trend towards higher ad libitum intake on control treatments measured in Experiment 2 than in Experiment 1 (Fig. 2c), and live weight would normally increase in the spring as a consequence (Adam 2000). Thus the chronic 
maintenance level of food intake would have imposed an effectively greater restraint on appetite and live weight in the spring, and indeed it has been reported that i.c.v. leptin does not affect appetite in food-restricted sheep with low live weight (Henry et al. 2001, Morrison et al. 2001). The ability of exogenous leptin to inhibit appetite may simply be a function of the strength of the intrinsic appetite drive that it acts against, with consequent dose dependency. It is pertinent in this regard that in the present study we found a 'pharmacological' dose-response in autumn, with only the two higher leptin doses having an effect on appetite (Experiment 1), whilst one of the same 'effective' doses of leptin had no effect on appetite in spring (Experiment 2). Our 'physiological' leptin i.c.v. infusion (Experiment 3) also had no effect on intake in spring, reflecting the seasonal insensitivity across the dose range and in support of the positive dose-response relationship. Others have reported metabolic effects of i.c.v. leptin to be dose dependent; for example, a low dose suppressed weight gain by $15 \%$ without changing daily food intake in female rats whereas a twofold higher dose decreased body weight by $30 \%$ along with a reduction in daily food intake (Dhillon et al. 2001).

The foregoing discussion leads to the suggestion that there may be separate sub-populations of leptin target neurones influencing the appetite and GnRH axes. Additional support for this notion comes from the present responses to murine leptin, which appeared to have similar i.c.v. biological activity to the homologous peptide with respect to its ability to decrease LH pulse amplitude and to decrease appetite by $32 \%$ (albeit non-significantly) whereas, unlike ovine leptin, it failed to affect LH pulsatility (Experiment 1; Fig. 1). This suggests that variability can exist in leptin interactions with its receptor, leading to differential responses, in this case due to a small difference in the leptin amino acid sequence $(84 \%$ identical; Dyer et al. 1997).

In conclusion, i.c.v. leptin can stimulate $\mathrm{LH}$ secretion in adequately nourished sheep, with or without simultaneously inhibiting appetite. Both the appetite and $\mathrm{LH}$ responses are seasonally and dose dependent, yet the seasonal effect is distinct for each of these neuroendocrine axes. These results are consistent with distinct neural pathways mediating the effects of leptin on energy balance and on the reproductive neuroendocrine axis.

\section{Acknowledgements}

This study could not have been contemplated without the generous assistance of the following: Ngaire Dennison for veterinary and surgery assistance, Irene Robertson for surgery assistance, Deirdre Bourke and staff for veterinary care, Animal House staff for daily care and Mr Richard Scarborough (University of Aberdeen) for help in conducting the animal trials. We are grateful for the donation of the recombinant ovine leptin for these studies by Professor Arieh Gertler, The Hebrew University of Jerusalem, Israel, and we thank the NIDDK and Dr A F Parlow (Pituitary Hormones and Antisera Center, HarborUCLA Medical Center, CA, USA) for the recombinant murine leptin and LH radioimmunoassay reagents. We also thank Professor G B Martin (University of Western Australia) and Dr R Smith (University of Liverpool) for the loan of stereotaxic manipulators, and Dr J E Robinson (Babraham Institute) for lending syringe pumps. This work was funded by the Scottish Executive Environment and Rural Affairs Department.

\section{References}

Adam CL 2000 Nutritional and photoperiodic regulation of appetite and reproduction in seasonal domestic mammals. Reproduction in Domestic Animals 6 (Suppl) 1-8.

Adam CL \& Findlay PA 1998 Inhibition of luteinizing hormone secretion and expression of c-fos and corticotrophin-releasing factor genes in the paraventricular nucleus during insulin-induced hypoglycaemia in sheep. Journal of Neuroendocrinology 10 777-783.

Adam CL, Findlay PA \& Moore AH 1998 Effects of insulin-like growth factor-1 on luteinizing hormone secretion in sheep. Animal Reproduction Science 50 45-56.

Ahima RS, Kelly J, Elmquist JK \& Flier JS 1999 Distinct physiologic and neuronal responses to decreased leptin and mild hyperleptinemia. Endocrinology 140 4923-4931.

Ahima RS, Saper CB, Flier JS \& Elmquist JK 2000 Leptin regulation of neuroendocrine systems. Frontiers in Neuroendocrinology 21 263-307.

Ainslie DA, Morris MJ, Wittert G, Turnbull H, Proietto J \& Thorburn AW 2001 Estrogen deficiency causes central leptin insensitivity and increased hypothalamic neuropeptide Y. International Journal of Obesity and Related Metabolic Disorders 25 1680-1688.

Anderson KJ, Mason KL, McGraw TS, Theophilopoulos DT, Sapper MS \& Burchfield DJ 1999 The ontogeny of glutamate receptors and D-aspartate binding sites in the ovine CNS. Developmental Brain Research 118 69-77.

Atcha Z, Cagampang FR, Stirland JA, Morris ID, Brooks AN, Ebling FJ, Klingenspor M \& Loudon AS 2000 Leptin acts on metabolism in a photoperiod-dependent manner, but has no effect on reproductive function in the seasonally breeding Siberian hamster (Phodopus sungorus). Endocrinology 141 4128-4135.

Bennett PA, Lindell K, Karlsson C, Robinson IC, Carlsson LM \& Carlsson B 1998 Differential expression and regulation of leptin receptor isoforms in the rat brain: effects of fasting and oestrogen. Neuroendocrinology 67 29-36.

Blache D, Celi P, Blackberry MA, Dynes RA \& Martin GB 2000a Decrease in voluntary feed intake and pulsatile luteinizing hormone secretion after intracerebroventricular infusion of recombinant bovine leptin in mature male sheep. Reproduction, Fertility and Development 12 373-381.

Blache D, Tellam RL, Chagas LM, Blackberry MA, Vercoe PE \& Martin GB $2000 b$ Level of nutrition affects leptin concentrations in plasma and cerebrospinal fluid in sheep. Journal of Endocrinology 165 625-637.

Brief DJ \& Davis JD 1984 Reduction of food intake and body weight by chronic intraventricular insulin infusion. Brain Research Bulletin 12 571-575.

Clarke IJ \& Cummins JT 1982 The temporal relationship between gonadotropin releasing hormone $(\mathrm{GnRH})$ and luteinizing hormone (LH) secretion in ovariectomized ewes. Endocrinology 111 1737-1739. 
Clarke IJ, Tilbrook AJ, Turner AI, Doughton BW \& Goding JW 2001 Sex, fat and the tilt of the earth: effects of sex and season on the feeding response to centrally administered leptin in sheep. Endocrinology 142 2725-2728.

Daniel JA, Thomas MG, Hale CS, Simmons JM \& Keisler DH 2000 Effect of cerebroventricular infusion of insulin and (or) glucose on hypothalamic expression of leptin receptor and pituitary secretion of LH in diet-restricted ewes. Domestic Animal Endocrinology 18 177-185.

Davson H, Welch K \& Segal MB 1987 Physiology and Pathophysiology of the Cerebrospinal Fluid. London: Churchill Livingstone.

Dhillon H, Kalra SP \& Kalra PS 2001 Dose-dependent effects of central leptin gene therapy on genes that regulate body weight and appetite in the hypothalamus. Molecular Therapy 4 139-145.

Dyer CJ, Simmons JM, Matteri RL \& Keisler DH 1997 cDNA cloning and tissue-specific gene expression of ovine leptin, NPY-Y1 receptor, and NPY-Y2 receptor. Domestic Animal Endocrinology 14 295-303.

Ebling FJ \& Cronin AS 1998 Manipulations of glutamatergic (N-methyl-D-aspartate receptor) neurotransmission alter the rate of photoperiodically regulated sexual maturation in the male Siberian hamster. Biology of Reproduction 58 1-7.

Friedmann MI \& Granneman J 1983 Food intake and peripheral factors after recovery from insulin-induced hypoglycemia. American Journal of Physiology 244 R374-R379.

Gay VL, Mikuma N \& Plant TM 1993 Remote and chronic access to the third cerebral ventricle of the unrestrained prepubertal rhesus monkey. American Journal of Physiology 264 E476-E481.

Gertler A, Simmons J \& Keisler DH 1998 Large-scale preparation of biologically active recombinant ovine obese protein (leptin). FEBS Letters 422 137-140.

Henry BA, Goding JW, Alexander WS, Tilbrook AJ, Canny BJ, Dunshea F, Rao A, Mansell A \& Clarke IJ 1999 Central administration of leptin to ovariectomized ewes inhibits food intake without affecting the secretion of hormones from the pituitary gland: evidence for a dissociation of effects on appetite and neuroendocrine function. Endocrinology 140 1175-1182.

Henry BA, Goding JW, Tilbrook AJ, Dunshea FR \& Clarke IJ 2001 Intracerebroventricular infusion of leptin elevates the secretion of luteinising hormone without affecting food intake in long-term food-restricted sheep, but increases growth hormone irrespective of bodyweight. Journal of Endocrinology 168 67-77.

Hileman SM, Schillo KK \& Hall JB 1993 Effects of acute, intracerebroventricular administration of insulin on serum concentrations of luteinizing hormone, insulin, and glucose in ovariectomized lambs during restricted and ad libitum feed intake. Biology of Reproduction 48 117-124.

Karsch FJ, Bittman EL, Foster DL, Goodman RL, Legan SJ \& Robinson JE 1984 Neuroendocrine basis of seasonal reproduction. Recent Progress in Hormone Research 40 185-232.

Kimura M, Irahara M, Yasui T, Saito S, Tezuka M, Yamano S, Kamada M \& Aono T 2002 The obesity in bilateral ovariectomized rats is related to a decrease in the expression of leptin receptors in the brain. Biochemical and Biophysical Research Communications 290 1349-1353

Klingenspor M, Niggemann H \& Heldmaier G 2000 Modulation of leptin sensitivity by short photoperiod acclimation in the Djungarian hamster, Phodopus sungorus. Journal of Comparative Physiology 170 37-43.

Knight TW, Hall DRH \& Wilson LD 1983 Effects of teasing and nutrition on the duration of the breeding season in Romney ewes. Proceedings of the New Zealand Society of Animal Production 43 $17-19$.
Kumar V, Lincoln GA \& Tortonese DJ 1993 Effects of excitatory amino acid receptor agonists and antagonists on the secretion of melatonin, luteinizing hormone and prolactin in the ram. Journal of Neuroendocrinology 5 649-654.

Mann GE, Lamming GE \& Fray MD 1995 Plasma oestradiol and progesterone during early pregnancy in the cow and the effects of treatment with buserelin. Animal Reproduction Science 37 121-131.

Marie M, Findlay PA, Thomas L \& Adam CL 2001 Daily patterns of plasma leptin in sheep: effects of photoperiod and food intake. Journal of Endocrinology 170 277-286.

Martin G, Fisher J, Blackberry M, Boukhliq R, Hötzel M, Miller D, Shepherd K \& Walkden-Brown S 1994 Nutritional and photoperiodic control of testicular size in Suffolk and Merino rams. Animal Production in Australia 20427.

Merriam GR \& Wachter KW 1982 Algorithms for the study of episodic hormone secretion. American Journal of Physiology 243 E310-E318.

Miller DW, Blache D \& Martin GB 1995 The role of intracerebral insulin in the effect of nutrition on gonadotrophin secretion in mature male sheep. Journal of Endocrinology 147 321-329.

Morrison CD, Daniel JA, Holmberg BJ, Djiane J, Raver N, Gertler A \& Keisler DH 2001 Central infusion of leptin into well-fed and undernourished ewe lambs: effects on feed intake and serum concentrations of growth hormone and luteinizing hormone. Journal of Endocrinology 168 317-324.

Nagatani S, Guthikonda P, Thompson RC, Tsukamura H, Maeda KI \& Foster DL 1998 Evidence for GnRH regulation by leptin: leptin administration prevents reduced pulsatile LH secretion during fasting. Neuroendocrinology 67 370-376.

Nagatani S, Zeng Y, Keisler DH, Foster DL \& Jaffe CA 2000 Leptin regulates pulsatile luteinizing hormone and growth hormone secretion in the sheep. Endocrinology 141 3965-3975.

Nilsson C, Lindvall-Axelsson M \& Owman C 1991 Simultaneous and continuous measurement of choroid plexus blood flow and cerebrospinal fluid production: effects of vasoactive intestinal polypeptide. Journal of Cerebral Blood Flow and Metabolism 11 861-867.

Pelleymounter MA, Baker MB \& McCaleb M 1999 Does estradiol mediate leptin's effects on adiposity and body weight? American Journal of Physiology 276 E955-E963.

Pollay M, Stevens A, Estrada E \& Kaplan R 1972 Excorporeal perfusion of choroid plexus. Journal of Applied Physiology 32 612-617.

Russel AJF, Doney JM \& Gunn RG 1969 Subjective assessment of body fat in live sheep. Journal of Agricultural Science 72 451-454.

Shanley LJ, Irving AJ \& Harvey J 2001 Leptin enhances NMDA receptor function and modulates hippocampal synaptic plasticity. Journal of Neuroscience 21 RC186.

Vanderweele DA, Pi-Sunyer F-X, Novin D \& Bush MJ 1980 Chronic insulin infusion suppresses food ingestion and body weight gain in rats. Brain Research Bulletin 5 7-12.

Viguie C, Caraty A, Locatelli A \& Malpaux B 1995 Regulation of luteinizing hormone-releasing hormone $(\mathrm{LHRH})$ secretion by melatonin in the ewe. II. Changes in N-methyl-D,L-aspartic acid-induced LHRH release during the stimulation of luteinizing hormone secretion by melatonin. Biology of Reproduction $\mathbf{5 2}$ 1156-1161.

Williams LM, Adam CL, Mercer JG, Moar KM, Slater D, Hunter L, Findlay PA \& Hoggard N 1999 Leptin receptor and Neuropeptide $\mathrm{Y}$ gene expression in the sheep brain. Journal of Neuroendocrinology 11 165-169.

Received 22 May 2002

Accepted 1 July 2002 